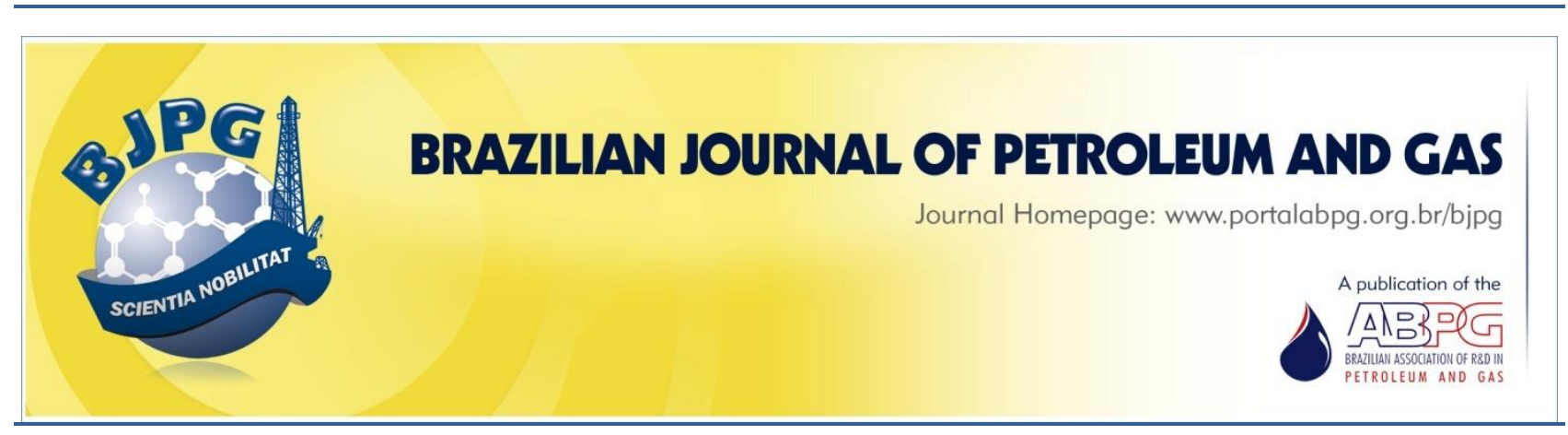

\title{
THE USE OF COBALT/RUTHENIUM CATALYST SUPPORTED IN SBA-15 IN THE PROMOTION OF FISCHER-TROPSCH SYNTHESIS
}

\author{
${ }^{\text {a }}$ Rodrigues, J. J. ${ }^{1}{ }^{\text {b }}$ Fernandes, F. A. N.; ${ }^{\text {a }}$ Rodrigues, M. G. F. \\ ${ }^{\text {a }}$ Federal University of Campina Grande, Academic Unit of Chemical Engineering, Pombal - PB - Brazil \\ ${ }^{b}$ Federal University of Ceará, Department of Chemical Engineering, Fortaleza- CE - Brazil \\ Received: 10.10.2019 / Revised: 01.03.2020 / Accepted: 05.03.2020 / Published on line: 06.05.2020
}

\begin{abstract}
The aim of this work is to produce a cobalt/ruthenium catalyst supported in SBA-15, for Fischer-Tropsch synthesis (FTS). The synthesis was carried out in a slurry reactor operating at $513 \mathrm{~K}, 20 \mathrm{~atm}$, and $\mathrm{CO}: \mathrm{H}_{2}$ molar ratio of 1:1. The addition of cobalt in SBA-15 decreased the specific superficial area of the molecular sieve. The ranges of temperature reduction typical of iron oxides phases were found using RTP results. Fischer-Tropsch synthesis activity and $\mathrm{C}_{5}{ }^{+}$hydrocarbon selectivity increased with the addition of $\mathrm{Ru}$. The increase in activity and selectivity were attributed to the increased number of active sites as a result of the higher reducibility.
\end{abstract}

\section{KEYWORDS}

SBA-15; ruthenium; rice husk ashes; slurry bed reactor; Fischer-Tropsch synthesis

\footnotetext{
${ }^{1}$ To whom all correspondence should be addressed.

Address: Federal University of Campina Grande, Academic Unit of Chemical Engineering, Rua Jairo Vieira Feitosa, 1770 Pereiros, Pombal - Paraíba - Brazil.

ZIP Code: 58840-000 | Phone/Fax number: +55(83) 3431-4085 | e-mail: jocielysr@gmail.com / jocielys@yahoo.com.br doi:10.5419/bjpg2020-0002
} 


\section{INTRODUCTION}

Changes in technological and energetic developments have led to a search for new routes for fuel production, as well as to the optimization of the use of existing technologies. The processes called Synthesis Gas Reactors- XTL, where X represents the carbon source to be used, are capable of converting carbon into liquid hydrocarbons. In this scenario, natural gas, coal, and biomass can be used as $X$, a carbon source. The processes involving the conversion of natural gas into liquid are called gas-to-liquid (GTL). These processes are also referred to as "coal-to-liquid" (CTL) when they use coal and biomass-to-liquid (BTL) when they use biomass as a carbon source (Chen et al., 2018; Gavrilovic et al., 2018; Kliewer et al., 2018; Rytter et al., 2018).

Fischer-Tropsch synthesis is becoming a key industrial process for producing a crude-oil independent supply used in high-quality liquid fuels. This process fulfills modern environmental requirements by exploiting abundant and renewable sources such as natural gas and biomass. Fischer-Tropsch synthesis (FTS) is receiving renewed attention, due to the global need to convert natural gas and nonpetroleumbased energy resources into fuels and chemicals (Jiang et al., 2018; Lliut et al., 2018; Steynberg et al., 2018; Zhang et al., 2018; Phaahlamohlaka et al., 2018).

Fe and Co are the two main classical catalysts used in the hydrogenation of CO. Cobalt-based catalysts promote higher yields, have a longer shelf life (less deactivation than iron catalysts), and have negligible activity for the reaction of Shift. Catalysts containing cobalt present advantages against ironbased catalysts. Among these advantages are: the higher activity by weight of the metal, higher resistance to water deactivation, and the lower production of oxygenates. To improve the performance of these catalysts, the "promoters" are generally used (Mangaloğlu et al., 2018; Rodrigues et al., 2013; Zhao et al., 1998).

Cobalt is considered as the most favorable metal for the synthesis of long chain hydrocarbons due to its high activity, high selectivity to linear paraffins, and low water-gas shift (WGS) activity. The use of SBA-15 as a support for cobalt-based FTS catalyst has been recently studied by several researchers (Ghampson et al., 2010).
In recent years, various researches on materials used as catalyst support applied in FTS have achieved positive results. Special emphasis has been given to the SBA-15, a silica-based mesoporous material with uniform hexagonal channels ranging from 3 to $30 \mathrm{~nm}$, very narrow pore size distribution, and high surface area (600$\left.1000 \mathrm{~m}^{2} / \mathrm{g}\right)$. Interestingly, SBA-15 also has thicker pore walls and better hydrothermal stability than MCM-41. These features can be relevant for the FTS process because water is a by-product of the reaction (Mangaloğlu et al., 2018; Phaahlamohlaka et al., 2018; Rodrigues et al., 2013; Zhao et al., 1998).

Xiong et al. (2010) prepared highly dispersed Co/SBA-15 catalysts. The addition of a small amount of Ru promoter to Co/SBA-15 decreased the reduction temperature of both reduction steps $\left(\mathrm{CO}_{3} \mathrm{O}_{4} \rightarrow \mathrm{CoO}\right.$ and $\left.\mathrm{CoO} \rightarrow \mathrm{Co}^{\circ}\right)$ and suppressed the formation of $\mathrm{Co}^{2+}$ species. By increasing the ruthenium content, catalyst reducibility increased, and the surface enriched in cobalt atoms.

The raw material normally used as source of $\mathrm{Si}$ for the synthesis of the SBA-15 molecular sieve is TEOS (tetraethylorthosilicate). The silica source can be selected through criteria such as availability, chemical reactivity, and cost. Molecular sieves produced from alternative sources of silica represent a promising technology. They replace conventional silica source of high financial value (TEOS) for alternative sources of silica (RHA) which are abundant and have low cost. Silica obtained from rice husk has been used with great success as a raw material for producing catalysts, demonstrating its high technological potential. However, the use of silica in catalysis requires, in most cases, purification processes for the removal of minor components present in its composition. These processes involve, in general, heat and acid treatments (Chen et al. 2018; Loy et al. 2018; Nicodeme et al. 2018; Rodrigues et al. 2012).

The objective of this work is to investigate the effects of ruthenium promoter on Co/SBA-15 (TEOS and RHA) catalyst in Fischer- Tropsch synthesis. In this work, a slurry reactor operating under typical industrial conditions was used to assess the performance of the catalyst in the Fischer-Tropsch synthesis. 


\section{EXPERIMENTAL}

\subsection{Rice husk ashes (RHA) attainment: Thermal and chemical treatments}

Rice husk was subjected to thermal and acid treatments. Heat treatment is a process used to separate the silica from organic compounds present in rice husk. The acid treatment is a process to remove impurities of rice husk ashes. The rice husk, previously washed in running water, was put in muffle furnace at of $873 \mathrm{~K}$, in $373 \mathrm{~K}$ elevation level for 4 hours, at the final temperature. The rice husk ash, obtained by heat treatment, was treated with hydrochloric acid $1 \mathrm{M}$ at $373 \mathrm{~K}$ with stirring in a contact time of 2 hours and ratio of rice husk ashes/volume solution of $25 \mathrm{~g} / 500 \mathrm{~mL}$. The material was dried in oven for 12 hours at 333K.

\subsection{Preparation of SBA-15}

SBA-15 was synthesized according to the procedure reported in the literature (Rodrigues et al., 2013; Zhao et al., 1998). First, 2 g Pluronic P123 (Aldrich) was dissolved in $15 \mathrm{~g}$ deionized water and $60 \mathrm{~g}$ of $2 \mathrm{~mol} / \mathrm{L} \mathrm{HCl}$ solution while stirring. Then, $4.25 \mathrm{~g}$ silica source was added into the solution under constant stirring. This mixture was stirred continuously for $24 \mathrm{~h}$. The gel mixture was, then, transferred to a Teflon-lined autoclave and kept static at $368 \mathrm{~K}$ for two days. The product was centrifuged at $11000 \mathrm{rpm}$, washed with deionized water several times, and dried at $373 \mathrm{~K}$. The material was calcined in static air at $823 \mathrm{~K}$ for $2 \mathrm{~h}$ to remove the polymer template and to obtain white SBA-15 powder. The sample was synthesized with the following molar composition: 1.0 Silica source: $0.017 \mathrm{P} 123: 5.7 \mathrm{HCl}: 193 \mathrm{H}_{2} \mathrm{O}$.

\subsection{Preparation of Co/SBA-15 and $\mathrm{Ru} / \mathrm{Co} / \mathrm{SBA}-15$ catalysts}

Four catalysts were prepared: Co/SBA-15 catalyst (used as control catalyst) and $\mathrm{Ru} / \mathrm{Co} / \mathrm{SBA}$ 15 catalyst. Co/SBA-15 (TEOS and RHA) catalyst was prepared containing $20 \%(\mathrm{w} / \mathrm{w})$ Co and $\mathrm{Ru} / \mathrm{Co} / \mathrm{SBA}-15$ (TEOS and RHA) catalyst was prepared containing $0.5 \%(\mathrm{w} / \mathrm{w}) \mathrm{Ru}$ and $20 \%(\mathrm{w} / \mathrm{w})$ Co. The deposition of metal with $20 \%(w / w)$ Co on SBA-15 support was carried out by wet impregnation. A $0.1 \mathrm{~mol} / \mathrm{L}$ aqueous solution of cobalt nitrate $\left[\mathrm{Co}\left(\mathrm{NO}_{3}\right)_{2} \cdot 6 \mathrm{H}_{2} \mathrm{O}\right]$ was used to deliver the amount of cobalt to the support. The impregnation was carried out at room temperature for $30 \mathrm{~min}$ under continuous stirring. The mixture was dried at $353 \mathrm{~K}$ for $24 \mathrm{~h}$. The solid material was calcined at $473 \mathrm{~K}$ under a nitrogen flow rate of 100 $\mathrm{mL} /$ (gcat.min), with a heating ramp of $283 \mathrm{~K} / \mathrm{min}$ starting from room temperature, and kept at the final temperature for $1 \mathrm{~h}$. After this period, the nitrogen flow was replaced by synthetic air and the sample was heated again at $275 \mathrm{~K} / \mathrm{min}$ from $473 \mathrm{~K}$ to $723 \mathrm{~K}$, and kept at this temperature for $2 \mathrm{~h}$. $\mathrm{Ru} / \mathrm{Co} / \mathrm{SBA}-15$ catalyst was prepared by coimpregnation of SBA-15. First, $0.1 \mathrm{~mol} / \mathrm{L}$ aqueous solution of cobalt nitrate $\left[\mathrm{Co}\left(\mathrm{NO}_{3}\right)_{2} \cdot 6 \mathrm{H}_{2} \mathrm{O}\right]$ was used to deliver the amount of cobalt to the support. Afterwards, the impregnation of Ru was carried out using an aqueous solution of ruthenium-nitrosyl. $\mathrm{Ru} / \mathrm{Co} / \mathrm{SBA}-15$ catalyst was calcined using the same procedure described for the production of Co/SBA15 (Rodrigues et al., 2012).

\subsection{Characterization of samples}

$X$-ray energy dispersion spectrophotometer (EDX): Elemental analysis was determined through energy dispersive $\mathrm{X}$-ray spectrophotometry, in a Shimadzu EDX-700 instrument.

$X$-ray diffraction (XRD): Powder diffraction patterns were measured on a Shimadzu XRD 6000. The operational conditions were: Copper $\mathrm{K} \alpha$ radiation at $40 \mathrm{kV} / 30 \mathrm{~mA}$, goniometer velocity of $2 \%$ min with a step of $0.02 \mathrm{~K}$ over $2 \theta$ range from $275 \mathrm{~K}$ to $353 \mathrm{~K}$. The average diameter of the sample crystallites was determined by Scherre equation.

Analysis by temperature-programmed reduction (TPR): Calcined samples were characterized by TPR using a Micrometrics ChemiSorb 2720 instrument under a mixed $\mathrm{H}_{2}-\mathrm{N}_{2}$ flow $\left(5 \% \mathrm{H}_{2}\right.$ at $\left.30 \mathrm{~mL} / \mathrm{min}\right)$. Approximately $20 \mathrm{mg}$ of each sample were heated at $283 \mathrm{~K} / \mathrm{min}$ over the range of $293 \mathrm{~K}$ to $1273 \mathrm{~K}$. The samples were subjected to a pre-treatment before data acquisition, which consisted of heating from room temperature to $473 \mathrm{~K}(283 \mathrm{~K} / \mathrm{min})$, and keeping this temperature for $1 \mathrm{~h}$ under a $\mathrm{N}_{2}$ flow (30 $\mathrm{mL} / \mathrm{min})$.

Nitrogen adsorption (BET method): The textural characteristics of the catalyst were investigated by isothermal gas adsorption/desorption of $\mathrm{N}_{2}$ at $77 \mathrm{~K}$ using a Micrometrics ASAP 2020 equipment. The adsorption and desorption $\mathrm{N}_{2}$ isotherms were 


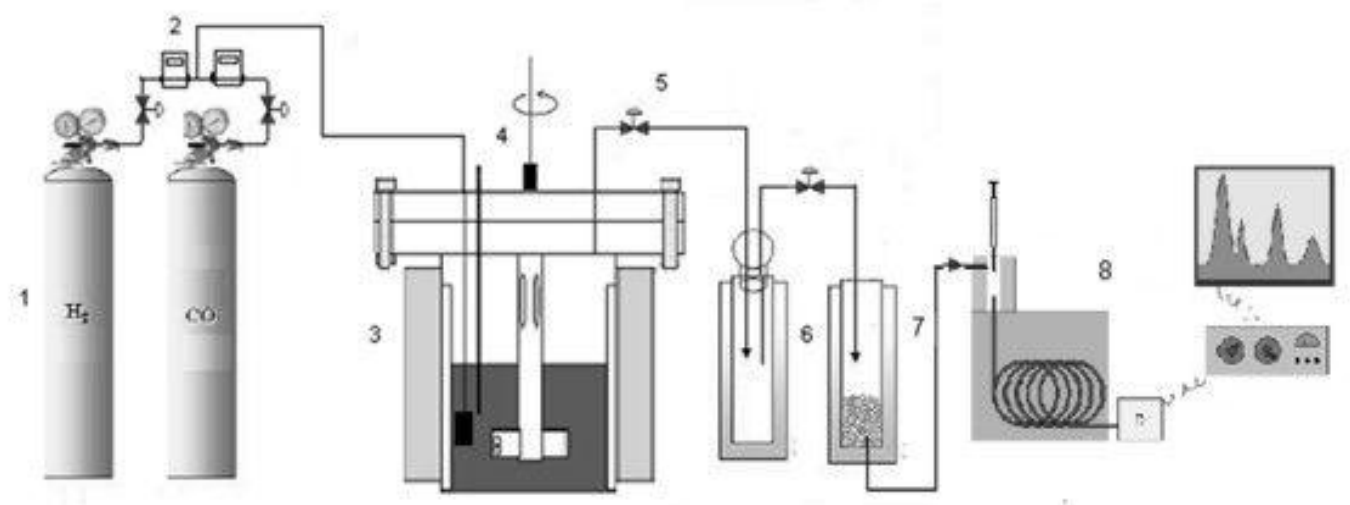

Figure 1. Scheme of the reaction system used to carry out the Fischer-Tropsch reaction. 1. Gas cylinders; 2 . Flow controllers; 3. Reactor; 4. Gas entrainement impeller and magnetic drive; 5. Outlet control valve; 6. High temperature trap; 7. Low temperature water trap; 8. Gas chromatograph (Rodrigues, 2013).

obtained in the range of relative pressure $\left(p / p_{0}\right)$ between 0.02 and 1.0. The values of the average pore diameter and surface area (SBET) were obtained by the proposed method (BET).

Transmission electron microscopy (TEM): The analyses were performed on JEOL equipment Model JEM-1200 EX II Instrument with the technique of embedding in Araldite resin and, then, cut with Sorvall MT 5000 ultramicron.

\subsection{Fischer-Tropsch Synthesis}

The Fischer-Tropsch Synthesis (FTS) was carried out in a stirred, semi-batch $500 \mathrm{~mL}$ autoclave reactor. The reaction was carried out with 3 grams of catalyst suspended in $150 \mathrm{~mL}$ of hexadecane in a high-pressure autoclave reactor (Parr Instruments model 4571). The hexadecane was inert under set reaction conditions. Tests were carried out at a total pressure $20 \mathrm{~atm}, 513 \mathrm{~K}$ (optimal condition for catalyst performance) with a $\mathrm{H}_{2}$ : $\mathrm{CO}$ feed ratio of 1:1 (Rodrigues et al. 2013). The gas synthesis was prepared by mixing $\mathrm{H}_{2}$ and $\mathrm{CO}$ through two mass flow controllers (Alborg GFC-17), enabling the desired $\mathrm{H}_{2} / \mathrm{CO}$ ratio to be obtained. The feed was introduced into the reactor below the agitator. The reaction was conducted under constant mechanical agitation (800 rpm) (Rodrigues et al., 2013), and a gas entrainment impeller was used to provide constant recirculation of the syngas to the slurry phase (Figure 1).

During catalytic experiments, the catalysts were reduced in situ at atmospheric pressure, prior to the addition of hexadecane, by increasing the temperature at a heating rate of $1 \mathrm{~K} / \mathrm{min}$ up to 673 $\mathrm{K}$, and maintained at this temperature for $10 \mathrm{~h}$ while passing a flow of pure hydrogen $(400$ $\mathrm{cm}^{3} / \mathrm{min}$ ) through the reactor. The reason for reducing $\mathrm{Co}$ at a very low heating rate (ten hours and in excess of hydrogen) is that cobalt oxide is more difficult to reduce (Rodrigues et al. 2012). After the reduction step, the temperature was lowered to $373 \mathrm{~K}$ under the flow of $\mathrm{H}_{2}$. Then, the reactant gas mixture $\left(\mathrm{H}_{2}: \mathrm{CO}\right)$ was introduced at a total flow rate of $250 \mathrm{~cm}^{3} / \mathrm{min}\left(\mathrm{H}_{2} / \mathrm{CO}=1\right)$, corresponding to a GHSV of $13.5 \mathrm{I}(\mathrm{NTP}) /\left(\mathrm{g}_{\text {cat }} \mathrm{h}\right)$ referred to the syngas feed. Reactor pressure was slowly increased up to 20 bar. Then, the temperature in the catalyst bed was increased from 373 to $513 \mathrm{~K}$ at a controlled heating rate of 4 $\mathrm{K} / \mathrm{min}$ to avoid instability of the system induced by the highly exothermic reaction.

The analysis of the products of the FTS was obtained after $6 \mathrm{~h}$ mass balance periods (after steady state was reached), allowing the accumulation of the liquid products in the reactor. Gas and liquid phase products were analyzed in a Gas chromatograph (Model Thermos Ultra), equipped with thermal conductivity (TCD) and flame-ionization (FID) detectors. Temperature programming ( $303 \mathrm{~K}$ to $573 \mathrm{~K}$ ) with an OV-1 capillary column $(30 \mathrm{~m} \times 0.25-\mathrm{mm}$ i.d. $\times 0.25-\mu \mathrm{m}$ film) allowed the identification of Fischer-Tropsch products $\left(C_{1}\right.$ to $\left.C_{40}\right)$. 

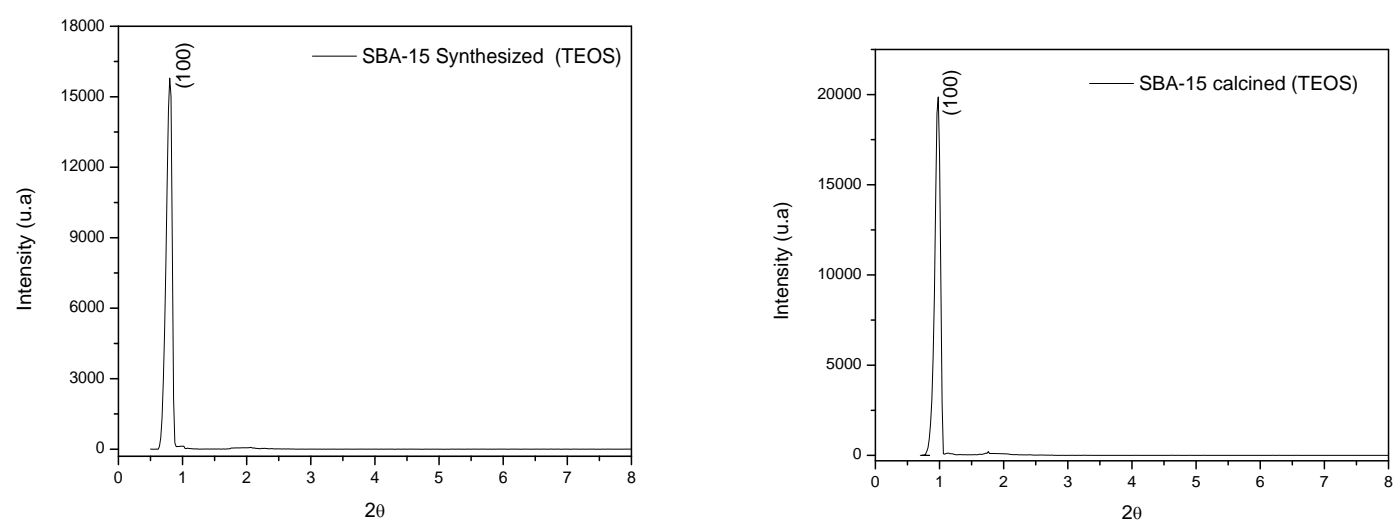

Figure 2. Diffractogram of synthesized and calcined SBA-15 (TEOS).
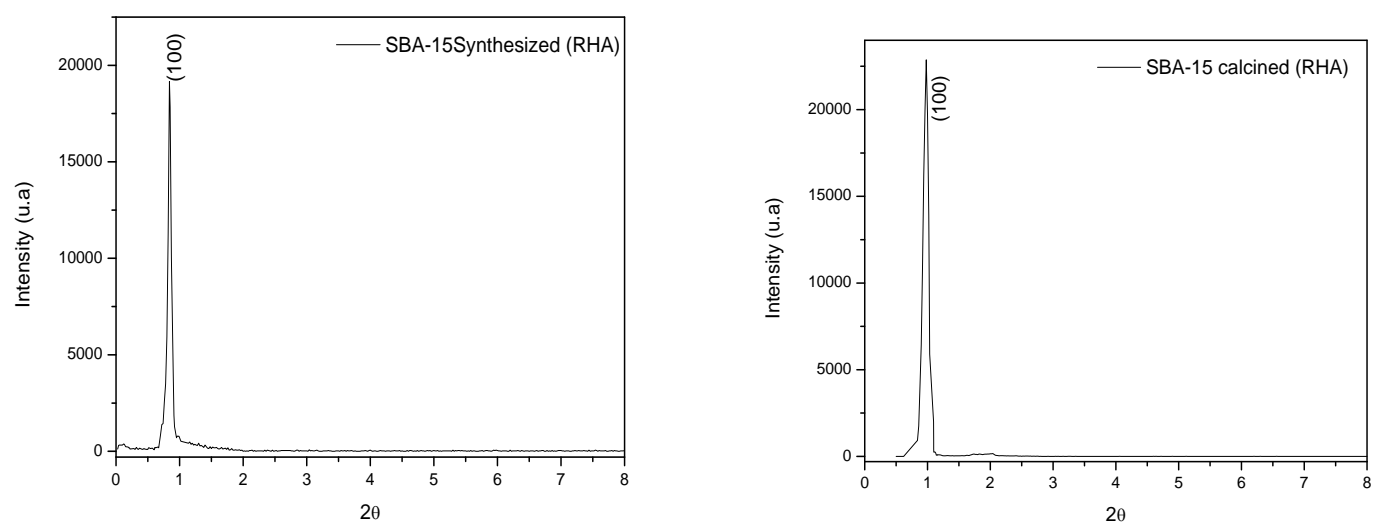

Figure 3. Diffractogram of synthesized and calcined SBA-15 (RHA).

The conversion of syngas into hydrocarbons was determined by mass balance of $\mathrm{CO}$, assayed using the same temperature programming with a Supelco Q-Plot capillary column $(30 \mathrm{~m} \times 0.25-\mathrm{mm}$ i.d. $\times 0.25-\mu \mathrm{m}$ film). A microcomputer used for performing data acquisition and process control also controlled automatic chromatograph sampling. The FTS product distribution was determined by mass balance of carbon species, which considered the conversion of syngas and mass fractions of hydrocarbon species in gas and liquid phases.

\section{RESULTS AND DISCUSSION}

X-ray diffraction profiles at samples (SBA-15 synthesized and calcined) obtained with TEOS and
RHA are shown in Figures 2 and 3, respectively. One can observe a pattern formation characteristic of the structure of a hexagonal symmetry typical p6mm SBA-15 (Gonzalez et al, 2009; Rodrigues et al., 2012; Zhao et al., 1998). The main diffraction peak, with Miller index of $\left(\begin{array}{lll}1 & 0 & 0\end{array}\right)$, referring to the crystal planes, characteristic of this type of material can be observed by XRD.

This shows that dissolution of the Pluronic P123 driver in water and hydrochloric acid under stirring and heating ( $308 \mathrm{~K}$ ) leads to the formation of copolymer /solvent interactions. After the addition of the silica source, silica /solvent interactions are formed to, then, form the silica / copolymer interactions. The gel obtained when subjected to the aging process for $24 \mathrm{~h}$ under agitation may result in, depending on the conditions of the solution (temperature, $\mathrm{pH}$ ), a siloxane phase by the 

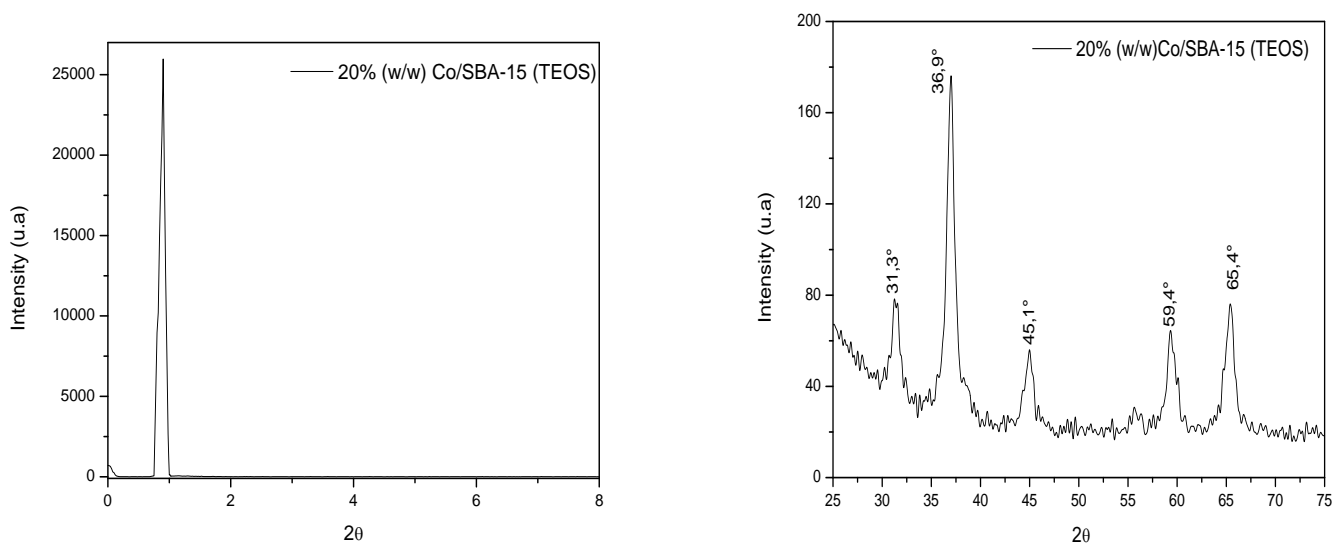

Figure 4. XRD patterns of the catalysts $20 \%$ (w/w) Co/SBA-15 (TEOS) after impregnation and calcinations.
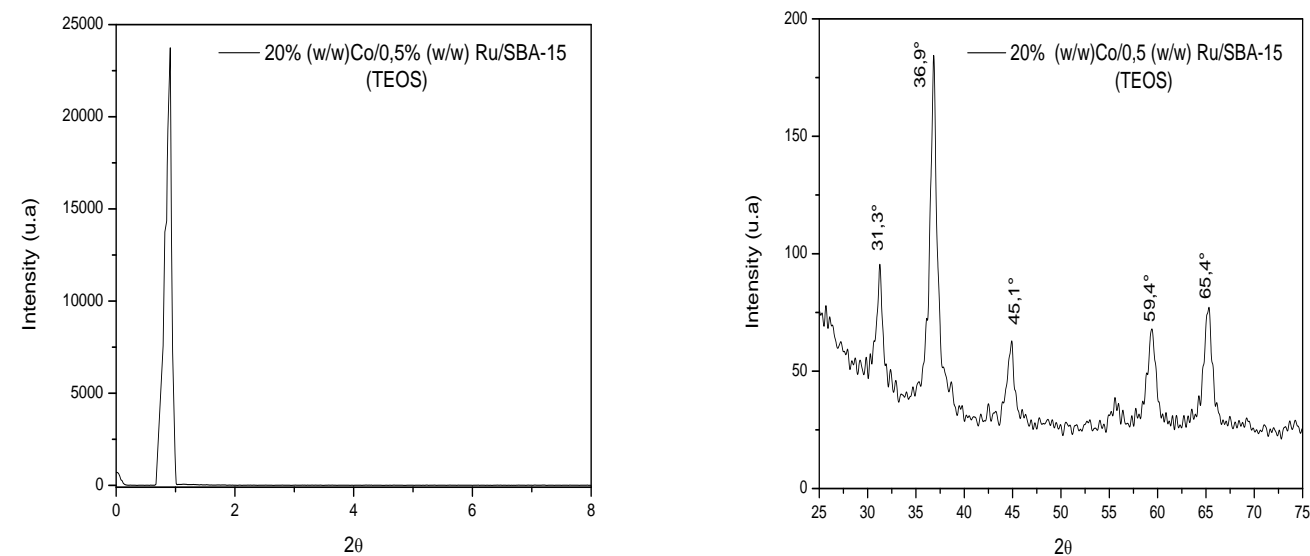

Figure 5. XRD patterns of the catalysts $20 \%(\mathrm{w} / \mathrm{w}) \mathrm{Co} / 0.5 \%(\mathrm{w} / \mathrm{w}) \mathrm{Ru} / \mathrm{SBA}-15$ (TEOS) after impregnation and calcinations.
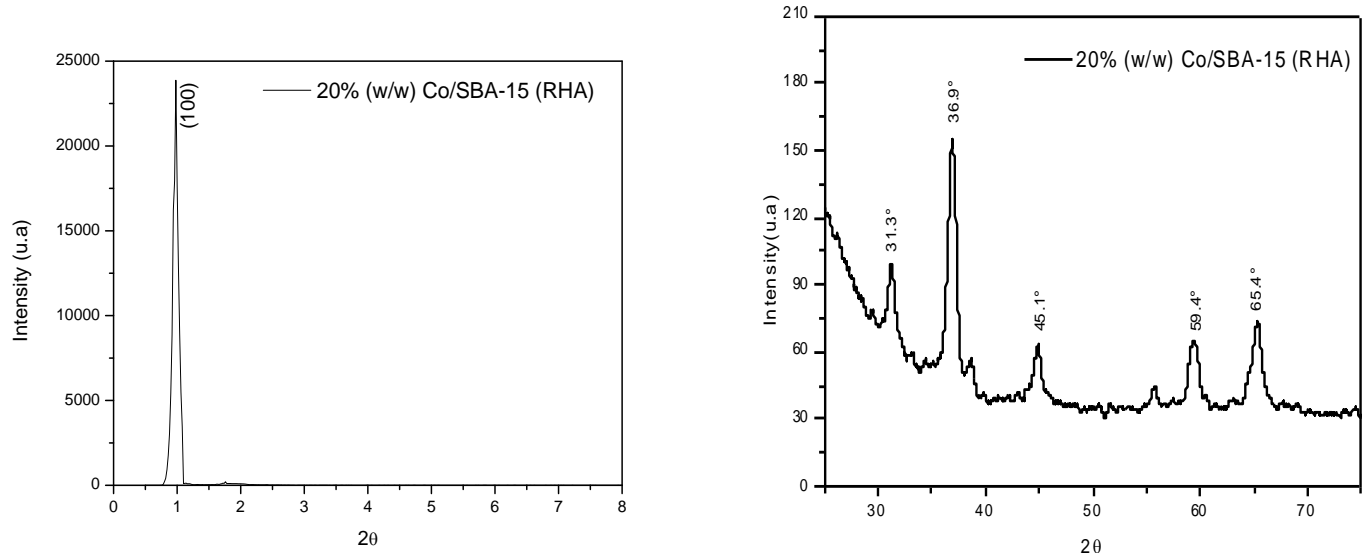

Figure 6. XRD patterns of the catalysts $20 \%(\mathrm{w} / \mathrm{w})$ Co/SBA-15 (RHA) after impregnation and calcinations.

condensation of the silica species on the micelles directing the copolymer. Thus, the gel can be subjected to a hydrothermal treatment to increase the thickness of the silica wall, forming the SBA-15 molecular sieve as verified by Figures 2 and 3 (Cai \& Li, 2008). X-ray diffraction profiles did not change significantly after impregnation with Co and co-impregnation with Ru. X-ray diffraction profiles presented high diffraction peaks showing that SBA15 has maintained its ordered structure after impregnation with cobalt and ruthenium Figure 4 and 5 (TEOS) and Figure 6 and 7 (RHA). 

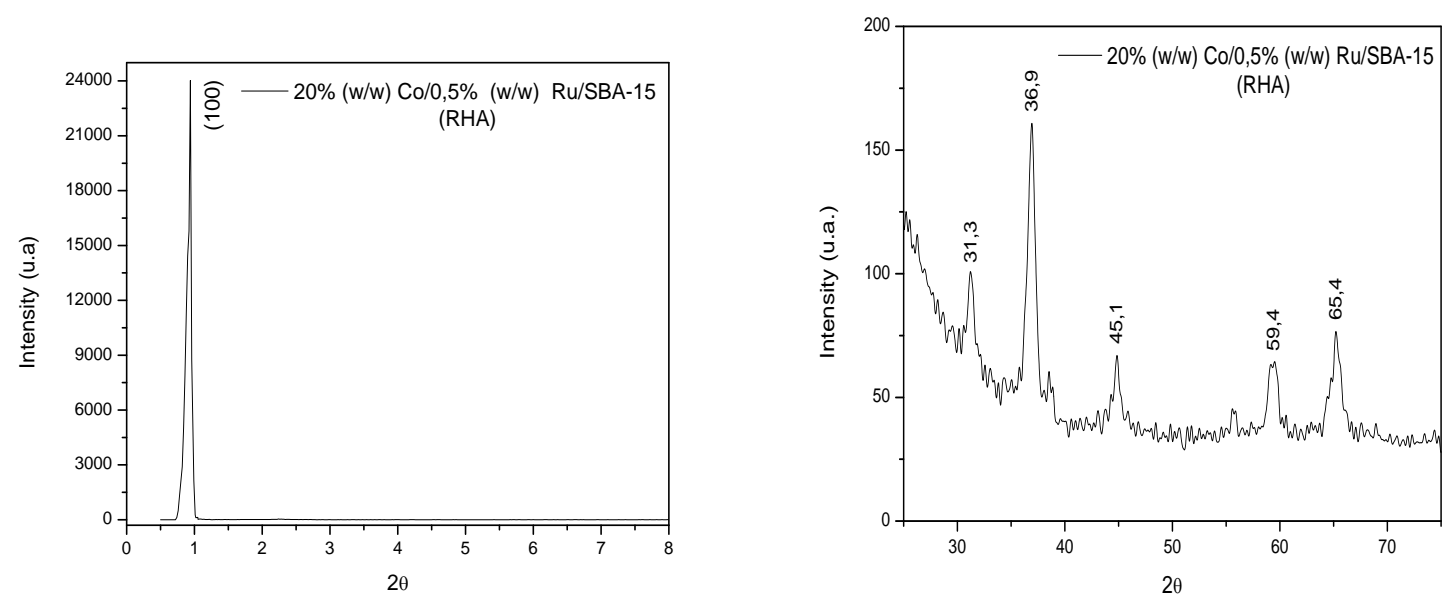

Figure 7. XRD patterns of the catalysts $20 \%(\mathrm{w} / \mathrm{w}) \mathrm{Co} / 0.5 \%(\mathrm{w} / \mathrm{w}) \mathrm{Ru} / \mathrm{SBA}-15$ (RHA) after impregnation and calcinations.

Cobalt nitrate is transformed into cobalt oxide during calcination under synthetic air environment. At temperatures above $473 \mathrm{~K}$, cobalt nitrate decomposed releasing $\mathrm{NOx}$ and $\mathrm{Co}^{2+}$ ions were converted into $\mathrm{CO}_{3} \mathrm{O}_{4}$, as reported by (Chen et al., 2018; Ghampson et al. 2010). The presence of peaks indicating the formation of $\mathrm{CO}_{3} \mathrm{O}_{4}$ species in Co/SBA-15 catalyst was identified using JCPDS-ICDD library (International Centre for Diffraction Data). The presence of peaks at $\mathrm{Co}_{3} \mathrm{O}_{4}\left(2 \theta=31.3^{\circ} ; 36.9^{\circ}\right.$; $45.1^{\circ} ; 59.4^{\circ}$; and $65.4^{\circ}$ ).

The chemical composition of SBA-15 and the catalysts are presented in Table 1 . The support and the catalysts have presented high levels of silica $\left(\mathrm{SiO}_{2}\right)$, which was expected because the structure of SBA-15 molecular sieve consists solely of silica. After impregnation of cobalt on SBA-15 at a $20 \%$ $(\mathrm{w} / \mathrm{w})$ nominal level of cobalt, it was possible to verify the presence of cobalt oxide $\left(\mathrm{CO}_{3} \mathrm{O}_{4}\right)$ in the samples.

The average crystallite sizes of $\mathrm{CO}_{3} \mathrm{O}_{4}$ are presented in Table 2. The crystallite diameter decreased slightly with the addition of $\mathrm{Ru}$, indicating that $\mathrm{Ru}$ have facilitated the dispersion of $\mathrm{CO}_{3} \mathrm{O}_{4}$ on the catalyst surface (Rodrigues et al., 2012).

The textural analysis of the calcined SBA-15 support and the catalysts is presented in Table 3. The specific area and total specific pore volume of

Table 1. Chemical composition of SBA-15 and catalysts.

\begin{tabular}{|c|c|c|c|c|}
\hline Samples & $\mathrm{SiO}_{2}$ & $\mathrm{CO}_{3} \mathrm{O}_{4}$ & Co & Impurities \\
\hline $20 \%$ (w/w) Co/SBA-15 (TEOS) & 71.10 & 28.30 & 20.1 & 0.6 \\
\hline $\begin{array}{l}20 \%(w / w) \text { Co } / 0.5 \%(w / w) \text { Ru/SBA- } \\
15 \text { (TEOS) }\end{array}$ & 71.00 & 27.30 & 19.4 & 1.7 \\
\hline $20 \%(w / w)$ Co/SBA-15 (RHA) & 68.45 & 29.35 & 20.9 & 2.2 \\
\hline $\begin{array}{l}20 \%(w / w) C o / 0.5 \%(w / w) ~ R u / S B A-15 \\
(R H A)\end{array}$ & 68.20 & 28.96 & 21.3 & 2.8 \\
\hline
\end{tabular}

Table 2. Average sizes of crystallites.

\begin{tabular}{lc}
\hline \multicolumn{1}{c}{ Catalysts } & Average crystallite size (nm) \\
\hline $20 \%(w / w)$ Co/SBA-15 (TEOS) & 18.5 \\
$20 \%(w / w)$ Co/0.5\% (w/w) Ru/SBA-15(TEOS) & 11.1 \\
$20 \%(w / w)$ Co/SBA-15 (RHA) & 20.6 \\
$20 \%(w / w)$ Co/0.5\% (w/w) Ru/SBA-15 (RHA) & 12.2 \\
\hline
\end{tabular}


Table 3. Textural analysis of the calcined SBA-15 calcined and catalysts.

\begin{tabular}{lcc}
\hline \multicolumn{1}{c}{ Samples } & $\mathrm{S}_{\text {BET }}\left(\mathrm{m}^{2} / \mathrm{g}\right)$ & $\mathrm{V}_{\text {Ptotal }}\left(\mathrm{cm}^{3} / \mathrm{g}\right)$ \\
\hline $20 \%(\mathrm{w} / \mathrm{w})$ Co/SBA-15 (TEOS) & 443 & 0.73 \\
$20 \%(w / w)$ Co/0.5\% (w/w) Ru/SBA-15(TEOS) & 385 & 0.71 \\
$20 \%(w / w)$ Co/SBA-15 (RHA) & 463 & 0.70 \\
$20 \%(w / w)$ Co/0.5\% (w/w) Ru/SBA-15 (RHA) & 339 & 0.68 \\
\hline
\end{tabular}

the calcined SBA-15 molecular sieve given in Table 3 are typical of SBA-15 structures synthesized under similar conditions (Rodrigues et al., 2012).

The incorporation of cobalt in the support resulted in a sharp decrease in surface area. This decrease may be attributed to the dilution effect of the support caused by the presence of the supported cobalt oxide phase, and, in a minor extent, to a partial blockage of the support pores (especially micropores and mesopores) (Gonzalez et al., 2009; Rodrigues et al., 2013).

Figures 8, 9, and 10 show $\mathrm{N}_{2}$ adsorption/desorption isotherms at $77 \mathrm{~K}$ of the calcined SBA-15 and catalysts. The isotherms for the calcined SBA-15 sample were of type IV and exhibited a well-defined $\mathrm{H} 1$ hysteresis loop according to the IUPAC classification relative to the mesoporous materials. There is also a $\mathrm{H} 1$ hysteresis
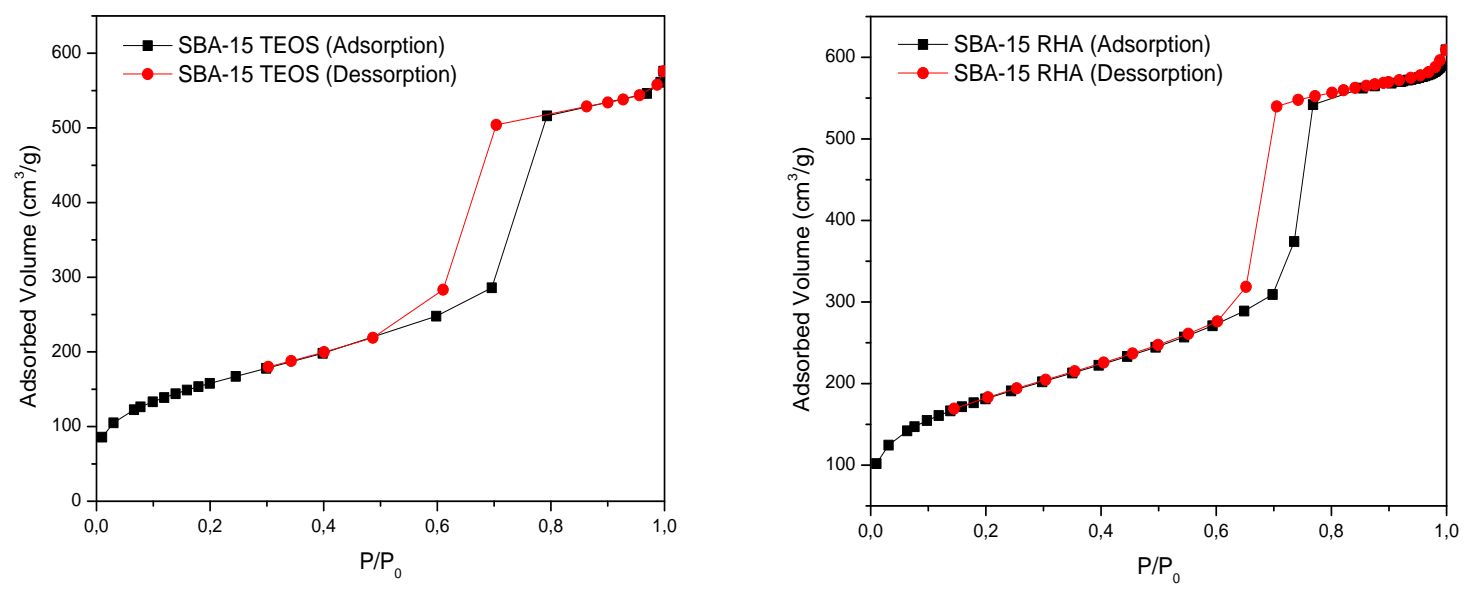

Figure 8. $\mathrm{N}_{2}$ adsorption/desorption isotherms of SBA-15 (TEOS) and SBA-15 (RHA) at $77 \mathrm{~K}$.
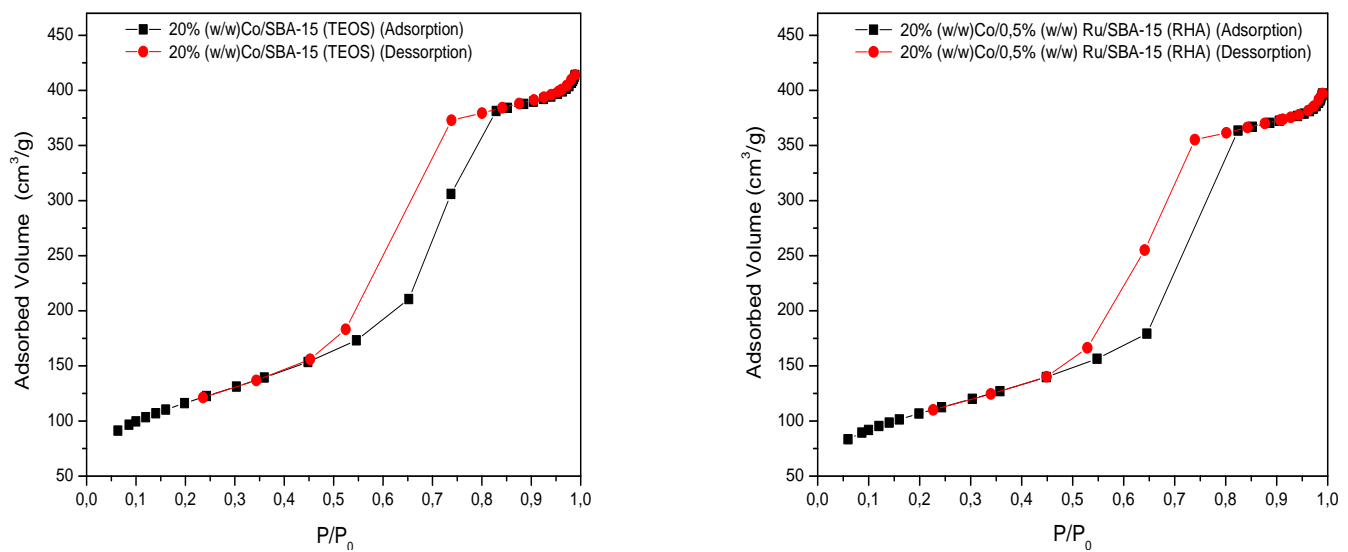

Figure 9. $\mathrm{N}_{2}$ adsorption/desorption isotherms of $20 \%(\mathrm{w} / \mathrm{w})$ Co/SBA-15 (TEOS) and 20\% (w/w) Co/0.5\% (w/w) $\mathrm{Ru} / \mathrm{Co} / \mathrm{SBA}-15$ (TEOS) at $77 \mathrm{~K}$. 

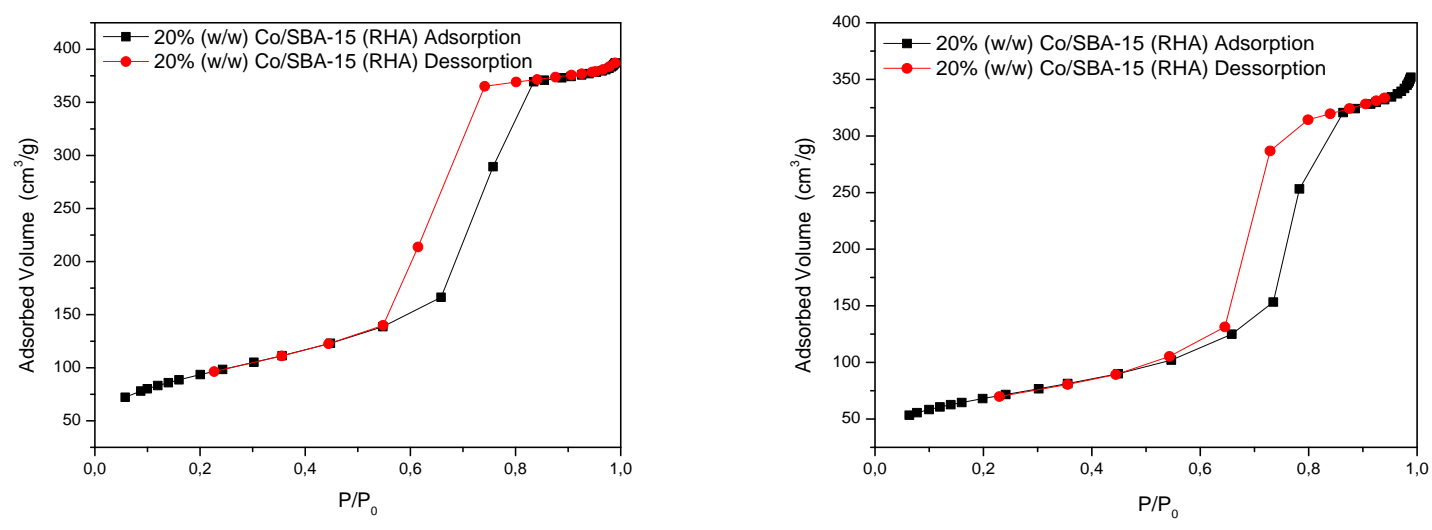

Figure 10. $\mathrm{N}_{2}$ adsorption/desorption isotherms of $20 \%(\mathrm{w} / \mathrm{w})$ Co/SBA-15 (RHA) and $20 \%(\mathrm{w} / \mathrm{w}) \mathrm{Co} / 0.5 \%(\mathrm{w} / \mathrm{w})$ $\mathrm{Ru} / \mathrm{Co} / \mathrm{SBA}-15$ (RHA) at $77 \mathrm{~K}$.
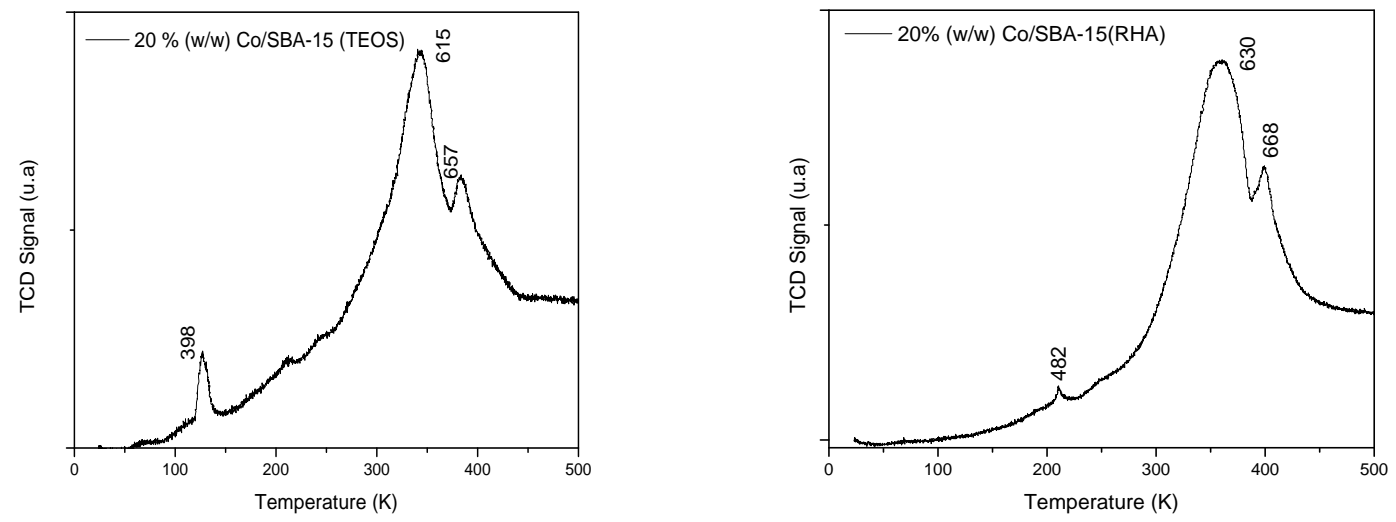

Figure 11. TPR profiles of the catalysts $20 \%$ (w/w)Co /SBA-15 (TEOS) and $20 \%$ (w/w) Co/SBA-15 (RHA).

phenomenon characterized by two branches of quasi-vertical and parallel isotherms over a wide range of ordinate values (adsorbed quantity).

When comparing the SBA-15 molecular sieve isotherm obtained with RHA with that synthesized with TEOS, one can verify that there are no significant differences that could disclose the type IV isotherm and type $\mathrm{H} 1$ hysteresis characteristic of mesoporous materials. There is only a slight difference between the inflection obtained for the SBA-15 (RHA), which was between 0.60-0.77 while the SBA-15 (TEOS) showed inflection between 0.47-0.79. However, these ranges of values are within the values observed in the literature for SBA-15 prepared with conventional reagent (TEOS) (Rodrigues et al., 2012).

The isotherms for the catalysts showed similar profiles, typically of type IV. The desorption curve for this catalyst also showed a $\mathrm{H} 1$ hysteresis loop for partial pressures $\left(p / p_{0}\right)$ between 0.6 and 0.8 , which can be attributed to capillary condensation and evaporation in the internal mesoporous structure of the tubes (Rodrigues et al., 2012).

TPR profiles of catalysts $20 \%(w / w)$ Co/SBA- 15 (TEOS) and $20 \%(w / w)$ Co/SBA-15 (RHA) are shown in Figure 11. Analyzing the RPT profile of the catalyst $20 \%(\mathrm{w} / \mathrm{w})$ Co/SBA-15 (TEOS), we found that this catalyst presented reduction peaks located at approximately $398 \mathrm{~K}$ and $615 \mathrm{~K}$. This can be attributed to the reduction of $\mathrm{CO}_{2} \mathrm{O}_{3}$ in two phases $\left(\mathrm{CO}_{2} \mathrm{O}_{3}=>\mathrm{CoO}=>\mathrm{Co}^{\circ}\right)$. The peak located at approximately $657 \mathrm{~K}$ is related to the reduction of cobalt oxide $\left(\mathrm{Co}^{2+}\right.$ and $\left.\mathrm{CO}^{3+}\right)$ species, which interact with the support and are difficult to reduce (Gonzalez et al., 2009; Rodrigues et al., 2013). The $20 \%(w / w)$ Co/SBA-15 (RHA) catalyst showed the 

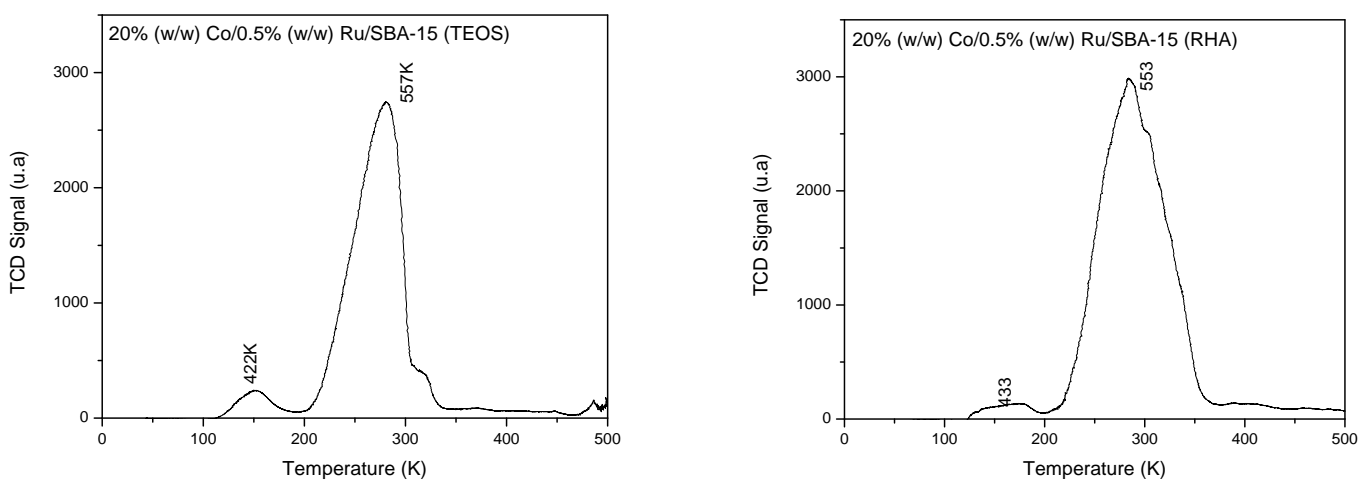

Figure 12. TPR profiles of the catalysts $20 \%(w / w)$ Co/0.5\%(w/w) Ru/SBA-15 (TEOS) and 20\% (w/w) Co/0.5\%(w/w) Ru/SBA-15 (RHA).
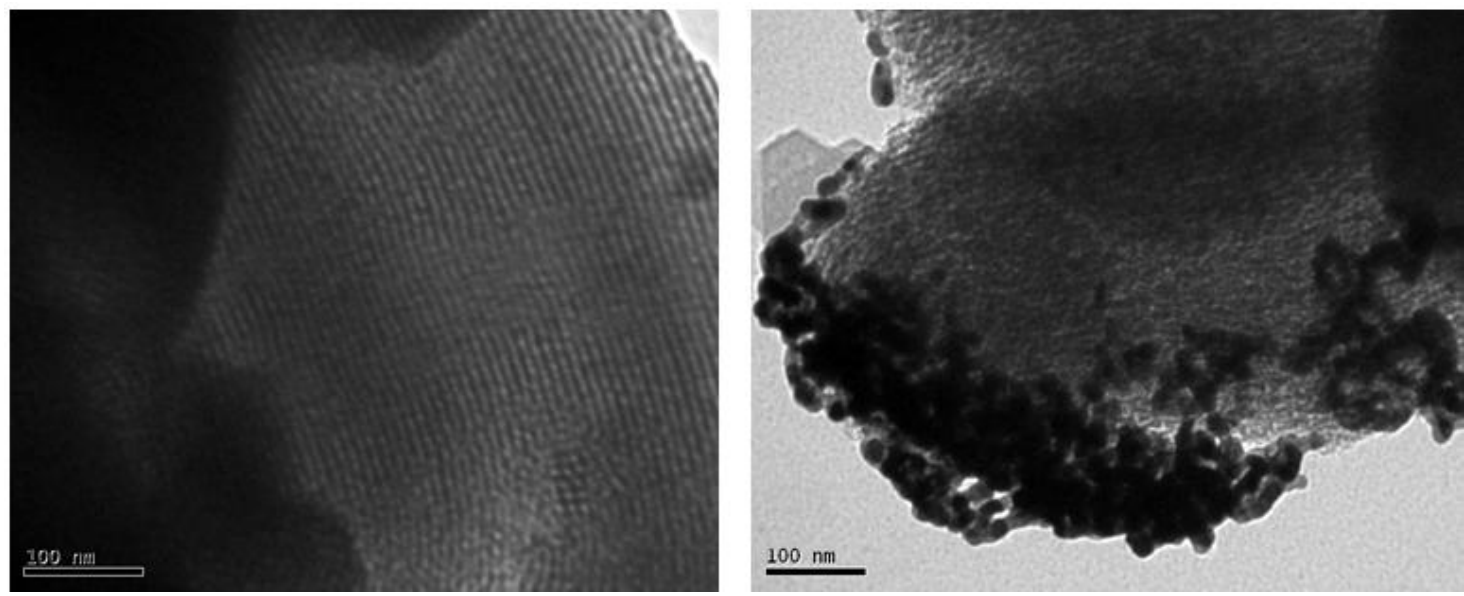

Figure 13. TEM micrographs $20 \%(w / w)$ Co/SBA-15 (TEOS).

first localized reduction peak at approximately $482 \mathrm{~K}$. This temperature is higher than that presented by the Co/SBA-15 (TEOS) catalyst. This may have occurred due to interactions between metal-support. In the second stage of reduction, the behavior similar to the Co/SBA-15 (TEOS) catalyst was observed, with a peak located at approximately $630 \mathrm{~K}$, corresponding to the $\mathrm{CoO}=>$ $\mathrm{Co}^{0}$ reduction. Similarly, the peak located at approximately $668 \mathrm{~K}$ occurred due to interactions of metal species with the support (Cai \& Li, 2008).

Noble metals can be reduced at temperatures lower than cobalt oxides. Thus, in its metallic state, the noble metals tend to favor the dissociation and the activation of the $\mathrm{H}_{2}$ and, in this way, benefit the cobalt reduction process (Cai \& Li, 2008).eTPR profiles of the catalysts $20 \%(\mathrm{w} / \mathrm{w}) \mathrm{Co} / 0.5 \%(\mathrm{w} / \mathrm{w})$ SBA-15 (TEOS) and $2020 \%(w / w) C o / 0.5 \%(w / w)$
SBA-15 (RHA) are shown in Figure 12. For the catalyst $20 \%(\mathrm{w} / \mathrm{w}$ ) Co/0.5\%(w/w) SBA-15 (TEOS), although there was no decrease in the temperature of reduction of $\mathrm{CO}_{3} \mathrm{O}_{4}$ species for $\mathrm{CoO}$, it was evident the decrease in temperature to obtain $\mathrm{Co}^{0}$. In the second stage, the temperature of reduction of this specie decreased significantly from $615 \mathrm{~K}$ to $557 \mathrm{~K}$.

Ruthenium favored the reduction of $\mathrm{CO}_{3} \mathrm{O}_{4}$ to $\mathrm{CoO}$, reducing the temperature of reduction of this species from $482 \mathrm{~K}$ to $433 \mathrm{~K}$, as can be seen in the first reduction peak. In the second stage, the reduction temperature of this species decreased significantly, from 630K to 553K.

The presence of ruthenium in the catalyst favored the elimination of the peak of hydrogen consumption located approximately between 657$668 \mathrm{~K}$, indicating that ruthenium favors the 

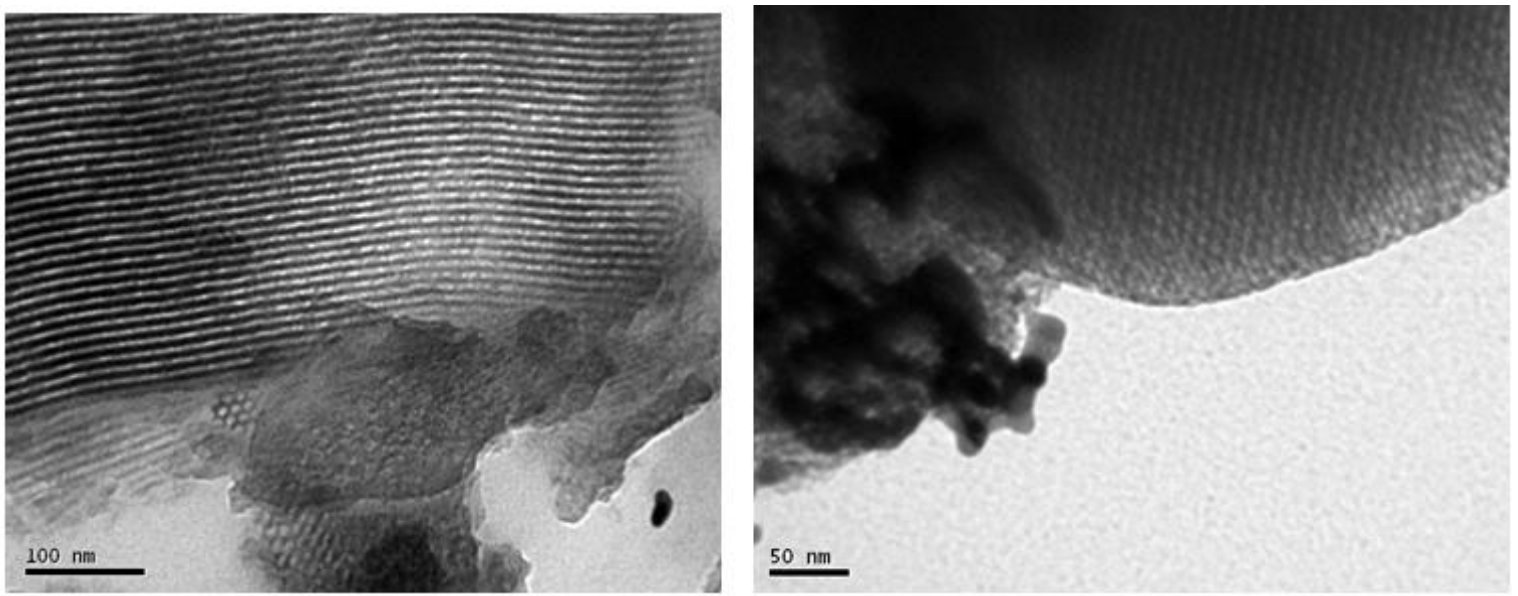

Figure 14. TEM micrographs $20 \%(w / w)$ Co/SBA-15 (RHA).

reduction of the interaction between cobalt oxide species $\left(\mathrm{CO}^{2+}\right.$ and $\left.\mathrm{CO}^{3+}\right)$ and the support (SBA-15). Thus, facilitating the reduction of these cobalt species that are difficult to reduce (Rodrigues et al., 2013).

TEM images representative of the catalysts $20 \%$ (w/w) Co/SBA-15 (TEOS) and 20\% 20\% (w/w) Co/SBA-15 (RHA), respectively, are shown in Figures 13 and 14 . In both cases, many agglomerations formed by spherical cobalt species with a size of $20 \mathrm{~nm}$ were observed. The edges the cobalt particles are irregular, and cobalt particles with smaller diameters are dispersed in the support, while larger ones agglomerated on the outer surface. The interplanar distances of these particles were $0.150 \mathrm{~nm}$, which is related to cobalt oxide ( $\mathrm{CoO})$. With these results, we can state that the diameter of the cobalt particles supported in SBA-15 is influenced by the pore diameter of the mesoporous silica, especially when it comes to samples prepared by wet impregnation, where size control does not occur (Cai \& Li, 2008).

Generally, metal fillers with high contents of the active phase on the catalytic supports tend to decrease the dispersion of the metal, forming large agglomerates of metal particles. This process can be further aggravated if there is a low interaction between the metal phase and the carrier, thus, increasing the mobility of the particles and, consequently, favoring the formation of metal particle agglomerates. No significant morphological changes were observed between Co/SBA-15 (TEOS) and Co/SBA-15 (RHA) catalysts.

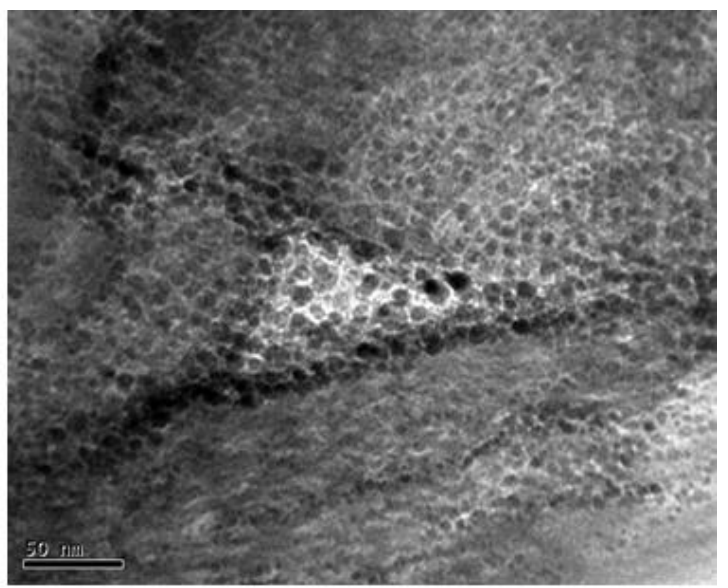

Figure 15. TEM micrographs of $20 \%(w / w)$ Co/0.5\% (w/w) Ru/SBA-15 (TEOS). 

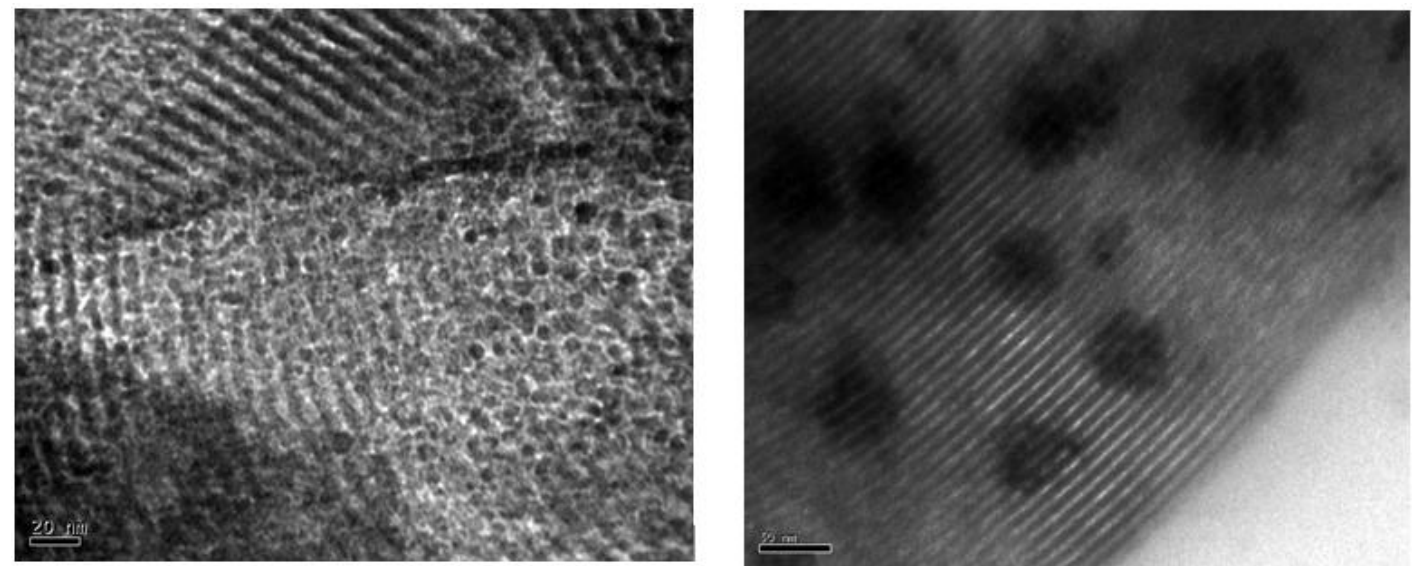

Figure 16. TEM micrographs of $20 \%(w / w)$ Co/0.5\% (w/w) Ru/SBA-15 (RHA).

TEM images of the catalysts $20 \%(\mathrm{w} / \mathrm{w}) \mathrm{Co} / 0.5 \%$ (w/w) Ru/SBA-15 (TEOS) and 20\% (w/w) Co/0.5\% (w/w) Ru/SBA-15 (RHA) after reduction are shown in Figure 15 and 16, respectively. In contrast, the addition of ruthenium as a promoter of the catalytic system tends not prevent the formation of large clusters with a defined shape. Thus, the addition of ruthenium increased the dispersion of the cobalt particles, reducing the size of the metal particles to $10 \mathrm{~nm}$. This was verified for both catalysts $20 \%(\mathrm{w} / \mathrm{w})$ Co/0.5\% (w/w) Ru/SBA-15 (TEOS) and 20\% (w/w) Co/0.5\% (w/w) Ru/SBA-15 (RHA). This occurred due to the intervention of ruthenium in the precursor kinetics of the precursor, altering the nucleation and crystallization of the cobalt oxide species and favoring the formation of smaller particles (Rodrigues et al., 2013).

The performance of the catalyst in FT synthesis is presented in Table 4. The catalyst with $\mathrm{Ru}$ promoter has presented a lower methane selectivity and higher $\mathrm{C}_{5}^{+}$hydrocarbon selectivity. The conversion of syngas into hydrocarbons has increased slightly with the addition of ruthenium to the catalyst (Rodrigues et al., 2013).

The results of catalyst activity in terms of syngas conversion $\left(\mathrm{X}_{\mathrm{CO}}\right)$ and selectivity in terms of hydrocarbon product distribution $\left(\mathrm{C}_{1}\right.$ to $\mathrm{C}_{5}{ }^{+}$, in \%), after 6 hours of reaction with the $20 \%(\mathrm{w} / \mathrm{w})$ $\mathrm{Co} / 0.5 \%(\mathrm{w} / \mathrm{w}) \mathrm{Ru} / \mathrm{SBA}-15$ catalyst, are shown in Table 4.

Results show that catalyst $20 \%(\mathrm{w} / \mathrm{w}) \mathrm{Co} / \mathrm{SBA}$ 15 (TEOS) presented an average conversion of 35\%, catalyst $20 \%(\mathrm{w} / \mathrm{w}) \mathrm{Co} / \mathrm{SBA}-15$ (RHA) obtained an average conversion of $36 \%$, and, as expected, $20 \%(w / w)$ Co $/ 0.5 \%(w / w)$ Ru/SBA-15 (TEOS) and $20 \%(w / w) \quad C o / 0.5 \% \quad(w / w) \quad R u / S B A-15 \quad$ (RHA) catalysts were obtained after the introduction of the promoter. This high conversion of the synthesis gas can be explained because the regular mesoporous structure has a beneficial effect on the mass transfer. The carrier chosen should allow the oxide species to be reduced in the presence of hydrogen. At the same time, there is a certain interaction that ensures the maintenance of the size distribution of metal particles on the surface of

Table 4. Catalytic performance of $20 \%(w / w)$ Co/SBA-15 and $20 \%(w / w)$ Co/0.5\% (w/w) Ru/SBA-15 catalysts in a slurry reactor for Fischer-Tropsch synthesis.

\begin{tabular}{|c|c|c|c|}
\hline Catalysts & XCO (\%) & $\mathrm{C}_{1}-\mathrm{C}_{4}$ & $\mathrm{C}_{5}^{+}$ \\
\hline $20 \%$ (w/w) Co/SBA-15 (TEOS) & 35 & 26.5 & 73.5 \\
\hline $20 \%(w / w)$ Co/SBA-15 (RHA) & 36 & 27.6 & 72.4 \\
\hline $20 \%(w / w)$ Co/0.5\% (w/w) Ru/SBA-15 (TEOS) & 40 & 18.5 & 81.5 \\
\hline 20\%(w/w) Co/0.5\% (w/w) Ru/SBA-15 (RHA) & 40 & 11.8 & 88.2 \\
\hline
\end{tabular}


the carrier. The overall conversion of $\mathrm{CO}$ appears to be related to the access of the reactants, while the selectivity relates to the olefin reinsertion capacity, which is directly linked to the metal-support interaction. Thus, an optimized catalyst would be one that can aggregate these two characteristics (Cai \& Li, 2008; Rodrigues et al., 2013). According to Furtado et al. (2013), the catalytic activity is linear to the loading of $\mathrm{Co}$ in the catalytic system employed in the Fischer-Tropsch synthesis. High metal contents lead to greater activities, which can be attributed to an increase of active sites. This allows us to assume that the metal dispersion did not undergo significant variations with the increase of the metal content in the catalyst.

Diffusion problems with reactants and products during the reaction may decrease activity and selectivity in long-chain hydrocarbons during Fischer-Tropsch synthesis. Results presented show that the selectivity in liquid hydrocarbons, for all the catalysts, is distributed in a very similar way. The catalysts $20 \% \quad(\mathrm{w} / \mathrm{w}) \quad$ Co/SBA-15 (TEOS) obtained selectivities around $26.5 \%$ for the $\mathrm{C} 1-\mathrm{C} 4$ range and $73.50 \%$ for the $\mathrm{C}_{5}{ }^{+}$range. The $20 \%(\mathrm{w} / \mathrm{w})$ Co/SBA-15 (RHA) catalyst presented selectivities values around $27.61 \%$ were obtained for the C1-C4 range and $73.39 \%$ for the $\mathrm{C}_{5}{ }^{+}$range. However, an increase in the selectivity for the $\mathrm{C}^{+}$fraction can be noted when the catalytic system was promoted with ruthenium. The introduction of ruthenium detracts from the production of hydrocarbons with chains between 1 and 4 carbons, mainly in the production of methane, which is the primary and undesirable product of the Fischer-Tropsch reaction. The concentration of metal in the catalyst can influence the distribution of $\mathrm{C}_{5}{ }^{+}$hydrocarbons. The selectivity in the fraction between $\mathrm{C} 5$ and $\mathrm{C} 12$ is favored by a higher cobalt concentration, which can be attributed to the increase in the number of active sites (Rodrigues et al., 2013).

However, the most interesting fact to be pointed out is that the use of this catalytic system with the catalyst prepared with an inexpensive and cheap silica source (rice hull ash) showed high selectivity in liquid products, that is, in hydrocarbons with $\mathrm{C}_{5}{ }^{+}$. Also, there was no formation of oxygenated products in this reaction. The catalyst $20 \%(\mathrm{w} / \mathrm{w})$ Co/0.5\% (w/w) Ru/SBA-15 (RHA) showed selectivity for the $\mathrm{C}_{5}^{+}$range around $88.17 \%$. The performance of this catalyst may have been due to the presence of ruthenium as catalyst promoter. It favored the reduction of cobalt species in the presence of hydrogen, assisted its dispersion, as well as increased the selectivity of $\mathrm{C}_{5}{ }^{+}$hydrocarbons.

\section{CONCLUSIONS}

The material obtained by the hydrothermal method using rice husk ashes as silica source showed typical features of SBA-15 molecular sieve, with a structure that includes multi-level mesopores, crystallites, and grains within the original particles. When cobalt is incorporated into the support, the properties of the final catalyst thereby prepared are close to theoretical values, demonstrating the efficiency of the wet impregnation technique.

With the addition of Ru, the activity of a catalyst for FT synthesis increased due to an increased reducibility of the catalyst and a synergistic effect between $\mathrm{Ru}$ and Co. The crystallite diameter decreased slightly with the addition of $\mathrm{Ru}$, indicating that $\mathrm{Ru}$ facilitated the dispersion of $\mathrm{CO}_{3} \mathrm{O}_{4}$ on the catalysts. The decrease in $\mathrm{C} 1-\mathrm{C} 4$ selectivity and the higher $\mathrm{C}_{5}^{+}$hydrocarbon selectivity were caused by the decrease of $\mathrm{Co}^{2+}$ and $\mathrm{Co}^{3+}$ species on the catalyst surface with the addition of ruthenium.

However, the most interesting finding is that the use of this catalytic system for the catalyst prepared with alternative and cheap silica source showed high selectivity in liquid products, that is, in hydrocarbons with $\mathrm{C}_{5}{ }^{+}$chains. No oxygenated products were formed in this reaction. The $20 \%$ (w/w) Co/0.5\% (w/w) Ru/SBA-15 catalyst showed selectivity for a $\mathrm{C}_{5}{ }^{+}$range around $88.2 \%$. The performance of this catalyst may be explained by the presence of ruthenium as catalyst promoter, since it favored a reduction of cobalt species in the presence of hydrogen, assisted its dispersion, and increased the selectivity of $\mathrm{C}_{5}{ }^{+}$hydrocarbons.

\section{ACKNOWLEDGMENTS}

The authors would like to make special acknowledgements to the Coordenação de Aperfeiçoamento de Pessoal de Nível Superior (CAPES), and Petrobras for their financial support to this research. 


\section{REFERENCES}

Cai, Q.; Li, J. Catalytic properties of the $\mathrm{Ru}$ promoted Co/SBA-15 catalysts forFischer-Tropsch synthesis. Catalysis Communications, v. 9, p. 20032006, 2008.

https://doi.org/10.1016/j.catcom.2008.03.035

Chen, W.; Lin, Y.; Daí, Y.; Na, Y.; Sun, Y. Recent advances in the investigation of nanoeffects of Fischer-Tropsch catalysts. Catalysis Today, v.311, p. 8-22, 2018.

https://doi.org/10.1016/i.cattod.2017.09.019

Furtado, J. L. B.; Carvalho, A.; Vieira, R. Carbon nanofibers as macroscopic catalyst support for Fischer-Tropsch synthesis. Advanced Chemistry Letters, v. 1, p. 317-320, 2013.

https://doi.org/10.1166/acl.2013.1035

Ghampson, I. T.; Newman, C.; Konk, L.; Pier, E.; Hurley, K. D.; Pollock, R. A.; Walsh, B. R.; Goundie, B.; Wright, J.; Wheeler, M. C.; Meulenberg, R. W.; Desisto, W. J.; Frederick, B. G.; Austin, R. N. Effects of pore diameter on particle size, phase, and turnover frequency in mesoporous silica supported cobalt Fischer-Tropsch catalysts. Applied Catalysis A: General, v. 388, p. 57-67, 2010.

https://doi.org/10.1016/i.apcata.2010.08.028

Gavrilovic, L.; Brandin, J.; Holmen, A.; Venvik, H.; Blekkan, E. Fischer-Tropsch synthesis Investigation of the deactivation of a Co catalyst by exposure to aerosol particles of potassium salt. Applied Catalysis B: Environmental, v. 230, p. 203209, 2018.

https://doi.org/10.1016/j.apcatb.2018.02.048

Gonzalez, O.; Perez, H.; Navarro, P.; Almeida, L.C.; Pacheco, J.G.; Montes, M. Use of different mesostructured materials based on silica as cobalt supports for the FischerTropsch synthesis. Catalysis Today, v. 148, p. 140-147, 2009.

https://doi.org/10.1016/i.cattod.2009.03.030

Jiang. Z.; Zhao, Y.; Huang, C.; Song, Y.; Liu, Z. Metal-support interactions regulated via carbon coating A case study of $\mathrm{Co} / \mathrm{SiO}_{2}$ for Fischer-Tropsch synthesis. Fuel, v. 226, p. 213-220, 2018.

https://doi.org/10.1016/i.fuel.2018.03.195

Kliewer, C. E.; Soled, S. L.; Kiss, G. Morphological transformations during Fischer-Tropsch synthesis on a titania-supported cobalt catalyst. Catalysis Today, v. 323, p. 233-256, 2019.

https://doi.org/10.1016/i.cattod.2018.05.021
Lliuta, I.; Larachi, F. Fischer-Tropsch synthesis in vertical, inclined and oscillating trickle-bed reactors for offshore floating applications. Chemical Engineering Science, v. 177, p. 509-522, 2018. https://doi.org/10.1016/i.ces.2017.12.012

Mangaloğlu, D. U.; Baranak, M.; Atac, O.; Atakul, H. J. Effect of the promoter presence in catalysts on the compositions of Fischer-Tropsch synthesis products. Journal of Industrial and Engineering Chemistry, v. 66, p. 298-310, 2018.

https://doi.org/10.1016/i.jiec.2018.05.044

Nicodeme, T.; Barchem, T.; Jacquet, N.; Richel, A. Thermochemical conversion of sugar industry by-products to biofuels. Renewable and Sustainable Energy Reviews, v. 88, p. 151-159, 2018. https://doi.org/10.1016/i.rser.2018.02.037

Phaahlamohlaka, T. N.; Dlamini, M. W.; Mogodi, M. W.; Kumi, D. O.; Coville, N. J.; A sinter resistant Co Fischer-Tropsch catalyst promoted with Ru and supported on titania encapsulated by mesoporous silica. Applied Catalysis A: General, v. 552, p. 129137, 2018.

https://doi.org/10.1016/j.apcata.2017.12.015

Rodrigues, J. J.; Pecchi, G.; Fernandes, F, A, N.; Rodrigues, $M, G, F$. Ruthenium promotion of Co/SBA-15 catalysts for Fischer-Tropsch synthesis in slurry-phase reactors. Journal of Natural Gas Chemistry, v. 21, p. 722-728, 2012.

https://doi.org/10.1016/S1003-9953(11)60425-8

Rodrigues, J.J.; Fernandes, F. A. N.; Rodrigues, M. G. F. Study of Co/SBA-15 catalysts prepared by microwave and conventional heating methods and application in Fischer-Tropsch synthesis. Applied Catalysis A: General, v. 468, p. 32-37, 2013. https://doi.org/10.1016/i.apcata.2013.08.035

Rytter, E.; Borg, Ø.; T, Sakoumis, N. E.; Holmen, A. Water as key to activity and selectivity in Co Fischer-Tropsch synthesis: $\gamma$-alumina based structure-performance relationships. Journal of Catalysis, v. 365, p. 334-343, 2018.

https://doi.org/10.1016/j.jcat.2018.07.003

Steynberg, A.; Deshmukh, S.; Bobota, H. FischerTropsch catalyst deactivation in commercial microchannel reactor operation. Catalysis Today, v. 299, p. 10-13, 2018.

https://doi.org/10.1016/i.cattod.2017.05.064 
Xiong, H.; Zhang, Y.; Liew, K., Li, J. FischerTropsch synthesis: The role of pore size for Co/SBA15 catalysts. Journal of Molecular Catalysis A: Chemical, v. 295, p. 68-76, 2010.

https://doi.org/10.1016/i.molcata.2008.08.017

Zhang, X.; Qian, W.; Zhang, H.; Sun, Q.; Ying, W.; Effect of the operation parameters on the FischerTropsch synthesis in fluidized bed reactors. Chinese Journal of Chemical Engineering, v. 26, p. 245-251, 2018. https://doi.org/10.1016/i.cjche.2017.05.012
Zhao, D.; Huo, Q.; Fend J, B, F.; Chmelka, G, D. Nonionic triblock and star diblock copolymer and oligomeric surfactant syntheses of highly ordered, hydrothermally stable, mesoporous silica structures. Journal of the American Chemical Society, v.120, p. 6024-6036, 1998.

https://doi.org/10.1021/ja974025i 